\title{
NARRATIVAS DIGITAIS E EXPERIÊNCIA: EXPLORAÇÃO DE CONCEITOS E IMPLICAÇÕES PARA A EDUCAÇÃO EM UMA PERSPECTIVA HUMANISTA ${ }^{1}$
}

\section{Alessandra RODRIGUES}

\begin{abstract}
RESUMO
Apesar da expansão das discussões sobre a temática das narrativas digitais, são ainda escassos os estudos dedicados a uma abordagem conceitual do tema. Este artigo resulta de uma revisão narrativa de literatura e apresenta um estudo teórico-conceitual acerca das "narrativas digitais" em diálogo com o conceito de "experiência" em Heidegger e Larrosa. O texto explora os dois conceitos em interlocução com autores que defendem uma educação humanista e emancipatória. A partir daí, indica caminhos para integração dessas narrativas à prática docente e aos currículos em diferentes contextos formativos. Nessa direção, pretende trazer contribuições teóricas apresentando as narrativas digitais como possibilidade didáticopedagógica e crítico-reflexiva para a construção de uma educação mediada pelas tecnologias que contribua para que o humanismo se mantenha como fundamento de nossas relações também no contexto da cultura digital.
\end{abstract}

PALAVRAS-CHAVE: Narrativas digitais; Experiência; Tecnologia Educacional; Humanismo.

\section{DIGITAL STORYTELLING AND EXPERIENCE: EXPLORING CONCEPTS AND IMPLICATIONS FOR EDUCATION FROM A HUMANIST PERSPECTIVE}

\begin{abstract}
Despite the expansion of discussions on the theme of digital storytelling, there are still few studies dedicated to a conceptual approach to the theme. This article is the result of a narrative review of the literature and presents a theoretical-conceptual study about "digital storytelling" in dialogue with the concept of "experience" in Heidegger and Larrosa. The text explores the two concepts in dialogue with authors who defend a humanist and emancipatory education. From there, it indicates ways to integrate these narratives into teaching practice and curricula in different training contexts. In this way, it intends to bring theoretical contributions by presenting digital storytelling as a didactic-pedagogical and critical-reflexive possibilities for the construction of an education mediated by technologies that contributes for humanism to remain as the foundation of our relationships also in the context of digital culture.
\end{abstract}

KEYWORDS: Digital storytelling; Experience; Educational Technologies; Humanism.

NARRATIVAS DIGITALES Y EXPERIENCIA: EXPLORANDO CONCEPTOS E IMPLICACIONES PARA LA EDUCACIÓN DESDE UNA PERSPECTIVA HUMANISTA

\begin{abstract}
RESUMEN
A pesar de la expansión de las discusiones sobre el tema de las narrativas digitales, hay pocos estudios dedicados a un enfoque conceptual del tema. Este artículo es el resultado de una revisión narrativa de
\end{abstract}

\footnotetext{
i Doutora em Educação: Currículo, pela PUC-SP. Professora Adjunta da Universidade Federal de Itajubá (UNIFEI). Docente permanente do Programa de Pós-Graduação em Educação em Ciências da UNIFEI, atuando na linha de pesquisa "Educação e Tecnologias". E-mail: letras.ale@ hotmail.com.
}

Revista e-Curriculum, São Paulo, v.18, n.2, p. 692-714 abr./jun. 2020 
la literatura y presenta un estudio teórico-conceptual sobre "narrativas digitales" en diálogo con el concepto de "experiencia" en Heidegger y Larrosa. El texto explora los dos conceptos en diálogo con autores que defienden una educación humanista y emancipadora. A partir de ahí, indica formas de integrar estas narrativas en la práctica docente y los planes de estudio en diferentes contextos de capacitación. En esta dirección, tiene la intención de aportar contribuciones teóricas que presenten las narrativas digitales como posibilidades didáctico-pedagógicas y de reflexión crítica para la construcción de una educación mediada por tecnologías que contribuyan al humanismo a permanecer como la base de nuestras relaciones también en el contexto de la cultura digital.

PALABRAS CLAVE: Narrativas digitales; Experiencia; Tecnología educativa; Humanismo.

\section{INTRODUÇÃO}

Ricoeur (1994) reflete que "O significado da existência humana não é apenas o poder de mudar ou dominar o mundo, mas também a habilidade de ser relembrado e recuperado no discurso narrativo" (RICOEUR, 1994, p. 218). Ao associar a narração ao próprio sentido da existência, o autor evoca o poder do ato narrativo na vida humana. Para tanto, Ricoeur nos remete à epopeia grega, à tragédia e à teoria aristotélica da ação para evidenciar a "[...] prioridade reconhecida ao 'eu posso falar', 'eu posso dizer' [...]" (RICOEUR, 2006, p. 83) e afirma que aprender a "narrar-se" pode ser visto como o benefício de uma apropriação crítica construída a partir desse "poder falar".

Em diálogo com a potência subjetiva do narrar-se, anunciada por Ricoeur (2006), Bruner (2001) postula que a “[...] importância da narrativa para a coesão de uma cultura é tão grande, muito provavelmente, quanto o é na construção da vida de um indivíduo" (BRUNER, 2001, p. 44). Essas proposições são corroboradas por Kearney (2012) ao explicitar que "[...] todo processo histórico é reconhecido como tal na medida em que pode ser recontado" (KEARNEY, 2012, p. 413).

No contexto contemporâneo, o narrar-se vem ganhando novos contornos desenhados pela efervescência e ubiquidade das Tecnologias Digitais de Informação e Comunicação (TDIC), já que as narrativas digitais são construídas em mídias que interseccionam “[...] duas áreas, os meios de comunicação e os computadores" (MARTINO, 2015, p. 211). Assim, ainda que continue propiciando a (re)significação do vivido e configurando-se como um espaço de construção subjetiva e intersubjetiva, a narrativa cada vez mais transforma e é transformada por essas tecnologias, a exemplo, por um lado, dos jogos digitais contemporâneos, convertidos em 'histórias jogáveis e abertas' porque alicerçados sobre narrativas; e, por outro, da multiplicidade de formas pelas quais é possível construir narrativas com recursos digitais e torná-las públicas 
também por esses recursos. Outra possibilidade que se amplia em função da digitalidade é a construção de narrativas em coautoria e em redes. Além das construções colaborativas, as TDIC ainda facilitam consideravelmente o trabalho de revisão e alteração permanente dos elementos da história num movimento de 'fazer/refazer' que pode trazer contribuições aos processos de ensino e de aprendizagem mediatizados pelas tecnologias.

Nesse cenário, é preciso se debruçar sobre esse 'novo' conceito de narrativa, a digital, para melhor compreendê-lo em suas especificidades e possiblidades para o campo da Educação em uma perspectiva humanista. Isso implica em mudar uma concepção subjacente ao receio de muitos educadores em relação às tecnologias: a de que sejam contrapostas a razão instrumental e a razão crítico-reflexiva, e passar a vê-las, como aponta Assmann (2000, p. 7), como "racionalidades conjugáveis e complementares" ultrapassando a ideia, muitas vezes ainda presente em muitos contextos educacionais, “[...] de que a mídia despersonaliza, anestesia as consciências e é uma ameaça à subjetividade" (p. 8).

É nesse rol de questões que este artigo, resultado de revisão narrativa de literatura (ROTHER, 2007), se dedica a apresentar uma reflexão teórica para o aprofundamento e a ampliação da compreensão do conceito de narrativa digital e suas possíveis implicações para a Educação em diálogo com um outro conceito: o de "experiência". Este, por sua vez, trazido à baila desde a perspectiva de Heidegger (2003) e de Larrosa (2002; 2004; 2011a; 2011b):

Fazer uma experiência com algo, com uma coisa, com um ser humano, com um deus, significa que esse algo nos atropela, nos vem ao encontro, chega até nós, nos avassala e nos transforma. "Fazer" não diz aqui de maneira alguma que nós mesmos produzimos e operacionalizamos a experiência. Fazer tem aqui o sentido de atravessar, sofrer, receber o que nos vem ao encontro, harmonizando-nos com ele. É esse algo que se faz, que se envia, que se articula (HEIDEGGER, 2003, p. 121).

Nessa direção, temos como questão orientadora deste estudo a busca por compreender o que caracteriza as narrativas digitais e qual pode ser o papel dessas narrativas na experiência de aprender em uma perspectiva humanista de educação. Dialogando com a narrativa tradicional como um dos nossos mecanismos mais primitivos para construção e compreensão do mundo (MURRAY, 2003), nossa hipótese nesta revisão é a de que a narrativa digital seria também capaz de unir universos distintos e muitas vezes postos em oposição na construção do conhecimento científico (especialmente na tradição mais positivista das ciências da natureza): 
razão e emoção, objetividade e subjetividade; contribuindo para uma educação mais humanista articulada com as tecnologias de nosso tempo.

\section{NARRATIVAS DIGITAIS: TECNOLOGIAS, LINGUAGENS E TEMPOS QUE SE}

\section{ALTERAM}

Vieira Pinto (2005) nos convida a pensar sobre os quatro principais sentidos do termo 'tecnologia': 1) como "logos da técnica" - o estudo, a ciência, a discussão da técnica; 2) como a técnica em si; 3) como conjunto de todas as técnicas de que dispõe uma sociedade; 4) como a ideologização da técnica.

Fischer (2007, p. 292), por sua vez, nos lembra que:

[...] falar em techné reafirma historicamente o gesto humano de criar ferramentas e instrumentos aos quais recorremos para [...] ultrapassar limites; talvez no limite, se trate do desejo de enfrentar a grande força contra a qual desde sempre lutamos: a morte, a finitude humana.

A perspectiva proposta por Fischer aproxima-se da segunda e talvez da terceira acepções apresentadas por Vieira Pinto, mas acrescenta um dado que parece relevante para pensarmos a relação TDIC/narrativas: a superação (ainda que parcial) da finitude. Assim como as tecnologias, a narrativa, como escritura de si, carrega em seu bojo certo desejo de perpetuação. Nazar (2006) corrobora essa ideia apontando que a função mais nobre das palavras é ser corpo (escrita), dar consistência aos pensamentos e torná-los eternos quando se silencia com a morte. "Escrever é como não haver morrido" (SKLIAR, 2016, p. 18).

No contexto contemporâneo, a mediação das TDIC também parece estar promovendo a “[...] 'radicalização do uso da escrita' e nossa sociedade parece tornar-se textualizada', isto é, passar para o plano da escrita" (MARCUSCHI, 2010, p. 17) - como vemos nas redes sociais, blogs, grupos virtuais de discussão, grupos de mensagens via celular, comunidades virtuais de aprendizagem etc. numa tentativa (ainda que inconsciente) de ser lembrado, recuperado, como aponta Ricoeur (1994) em sua existência virtual discursivo-narrativa.

Cabe enfatizar ainda que a constituição da tecnologia (em todos os seus significados) e da técnica são processos humanos que implicam na ação motora, imaginativa e reflexiva do ser humano (LIMA JUNIOR, 2005), assim como a escritura - o que fortalece as possibilidades de inter-relação entre tecnologia e narrativa, inserindo-nos na questão das narrativas digitais. “[...] 
Produzida[s] por meio das TDIC e numa textualidade eletrônica que é multimidiática, [nelas] o sujeito pode lançar mão de uma diversidade ainda maior de recursos para se expressar" (RODRIGUES; GONÇALVES, 2014, p. 216).

Nessa direção, Murray (2003) argumenta que as tecnologias digitais prometem remodelar a expressão narrativa dando continuidade ao trabalho dos contadores de histórias mais antigos, mas dentro de outro arcabouço e de uma variedade de novas formas de contar histórias. Assim, considerando que a narrativa pode realizar-se em suportes expressivos variados e não se concretiza somente no plano estético-literário, mas também em contextos funcionais de comunicação (COSTA, 2009), as narrativas digitais, tendo os suportes mais diversos, são terrenos férteis por sua textualidade eletrônica multimidiática e

[...] semioticamente híbrica, englobando o texto escrito, a exploração de suas possibilidades gráficas, as distintas mídias imagéticas (gráficas, fotográficas e videográficas) e o som. [...] Aí está um dos poderes mais significativos da escrita na nova mídia: reunir o texto com a imagem, assim como com outras mídias (SANTAELLA, 2007, p. 335).

Além disso, há que se considerar que, com as TDIC, a história do texto escrito recomeça e altera-se também sua vocação para a conservação e a fixidez (MACHADO, 2000). Trata-se, agora, "[...] de sua absorção na hipermídia e sua consequente transmutação de sólido em líquido, de fixo em escorregadio, instável, volátil” (SANTAELLA, 2007, p. 293). Nesse cenário, Chartier (1999) refere que a obra também não será mais a mesma. Uma vez inscrita em formas distintas, carregará também outros significados. Da mesma maneira, “[...] talvez os autores da era multimídia [...] sejam governados pela pluralidade das formas de apresentação do texto permitida pelo suporte eletrônico" (CHARTIER, 1999, p. 72).

Tendo em perspectiva todo esse contexto, volto-me às acepções teóricas sobre a narrativa digital (digital storytelling ${ }^{3}$ ), cujos sentidos e conceitos passo a apresentar apoiandome inicialmente em Clarke e Adam (2012, p. 159), quando referem que “[...] o termo 'digital storytelling' em educação relaciona-se com a aplicação de recursos multimídia em ambientes de aprendizagem para a produção de narrativas multimídia pelos estudantes" (tradução livre). Os autores detalham:

[...] a narrativa digital abrange todas as formas e processos narrativos produzidos e compartilhados digitalmente, incluindo narrativa, histórias somente com imagem, rádio-histórias para internet e podcasting, e narrativa multimídia integrando imagem, som e talvez texto (CLARKE; ADAM, 2012, p. 160, tradução livre). 
Essa multiplicidade de recursos e de integração de mídias possível nas narrativas digitais permite, conforme Carvalho (2008), uma relação mais individualizada com esses recursos, quando utilizados para contar a história, e possibilita aos sujeitos "[...] maior fidelidade às intenções comunicativas pretendidas" (CARVALHO, 2008, p. 52). A isso, acrescento que a narrativa digital possibilita a articulação, na história narrada, de diferentes contextos por meio da utilização de recursos hipermidiáticos que permitem associar objetividade e subjetividade, potencializando a hibridização de mídias (som, vídeo, texto, imagens etc.) para representar fatos encadeados num todo narrativo. Essa hibridização permitiria, ao autor da narrativa, representar mais amplamente as múltiplas facetas da experiência narrada e compartilhada/publicizada experienciando, assim, também uma outra forma de constituição autoral (RODRIGUES, 2017, 2019a).

Considerando as especificidades das narrativas digitais, Xu, Park e Baek (2011) referem que devido ao seu potencial para dar suporte aos resultados da aprendizagem, essas narrativas começaram a ser utilizadas em diversos contextos. Além disso, os autores descrevem três elementos principais desse tipo de histórias, conforme explicita o Quadro 1:

Quadro 1 - Principais Elementos das Narrativas Digitais

\begin{tabular}{|l|l|}
\hline \multicolumn{1}{|c|}{ Elemento } & \multicolumn{1}{c|}{ Característica } \\
\hline Flexibilidade & $\begin{array}{l}\text { As histórias podem proceder de uma forma não-linear, permitindo ao contador } \\
\text { de histórias e ao leitor uma ampla gama de opções de comunicação. }\end{array}$ \\
\hline Universalidade & $\begin{array}{l}\text { Refere-se à habilidade de um grande número de pessoas para utilizar a narração } \\
\text { digital como resultado da difusão rápida e generalizada das tecnologias de } \\
\text { gravação que se tornaram disponíveis na primeira década do século XXI. }\end{array}$ \\
\hline Interatividade $^{4}$ & $\begin{array}{l}\text { Diz respeito à formação de comunidades que descrevem o processo pelo qual } \\
\text { as histórias digitais podem ser criadas com as tecnologias disponíveis, muitas } \\
\text { vezes por meio da troca de material e de informação - o que facilita a co- } \\
\text { construção do conhecimento entre os vários membros de uma comunidade de } \\
\text { aprendizagem. }\end{array}$ \\
\hline
\end{tabular}

Fonte: Adaptado de Xu; Park; Baek (2011).

Pelos três elementos destacados no Quadro 1 fica evidente que os efeitos da digitalidade no contar histórias não são meramente instrumentais ou relativos à simples alteração de suporte textual - do analógico para o digital. As tecnologias agregam ao narrar componentes que passam a ser constitutivos do próprio processo de construção da narrativa, de como ela pode ser idealizada, materializada e disseminada por seus autores. Assim, as narrativas digitais:

[...] provocam transformações nas estruturas de representação do pensamento, potencializam a interação, a participação e a colaboração, interferem nos sistemas de interpretação e negociação. As narrativas digitais propiciam aos 
autores expandir a imaginação, a criatividade, o sentido estético e a imersão nas histórias contadas de modo distinto do que seria feito em uma narrativa linear, verbalizada pela oralidade, escrita tradicional ou sequência de imagens (ALMEIDA, 2018, p. 477).

Na área de design, Paul (2007) também busca identificar os elementos constituintes das narrativas digitais e apresenta-os como sendo: mídia, ação, relacionamento, contexto e comunicação. Esses elementos agregam aspectos relativos: aos suportes da narrativa (mídia); ao movimento do conteúdo narrado e à atitude do usuário/leitor em relação a esse conteúdo (ação); ao tipo de relação - aberta ou fechada - entre usuário e conteúdo (relacionamento); aos conteúdos adicionais inseridos por meio dos recursos hipermidiáticos (contexto); e à capacidade de conexão com os outros por meio do conteúdo digital (comunicação). Os componentes propostos por Paul (2007) também indicam alterações promovidas pelo uso de recursos tecnológicos e alguns desses elementos alinham-se aos apresentados no Quadro 1, a exemplo de "ação" e "relacionamento", que podem associar-se à "flexibilidade", assim como "comunicação" e "interatividade" estão diretamente ligadas entre si.

Robin (2008), por sua vez, trata as narrativas digitais como ferramentas poderosas para engajar professores e estudantes nos processos de ensino e de aprendizagem. Além disso, o autor afirma que as narrativas digitais vêm ajudando professores de diversas áreas do conhecimento a superar obstáculos na utilização produtiva das tecnologias em suas salas de aula e destaca três tipos de narrativas digitais: as pessoais, cujos enredos giram em torno de eventos significativos da vida do autor e costumam ter cargas e significados emocionais; as históricas, que informam ou instruem, utilizadas especialmente para transmitir conteúdos das diferentes áreas do conhecimento; e as narrativas que examinam eventos históricos, que podem ser criadas para narrar acontecimentos da história acrescentando profundidade e significado a eventos passados.

Os três tipos de narrativas digitais propostos por Robin guardam ainda outro potencial importante: a possibilidade de autoria. Esse aspecto amplia o lugar e a importância da narrativa digital no campo da Educação, na formação do sujeito, na reflexividade de seu processo formativo e na assunção da função-autor, conforme detalha Rodrigues (2017, 2019b). Esse narrar carregado de sentidos, imagens, signos, movimentos e sons - que traz, além do discurso escrito de seu autor, outros elementos (típicos da linguagem das TDIC) capazes de colocá-lo no mundo e ajudá-lo a contar tanto suas histórias de aprendizagem quanto as histórias de construções de conceitos científicos - contribui para a abertura do sujeito "ao mundo e aos 
outros" num gesto pelo qual se abre "[...] à relação dialógica em que se confirma como inquietação e curiosidade, como inconclusão em permanente movimento da História" (FREIRE, 1996, p. 136).

Além disso, do ponto de vista da utilização das TDIC, a produção de narrativas digitais demanda do autor a fluência tecnológica e o desenvolvimento de letramentos múltiplos (ALMEIDA; VALENTE, 2012). Diferentemente de outros gêneros biográficos e autobiográficos (como o memorial, a história oral, a história de vida etc.), a narrativa digital coloca em movimento a relação direta dos sujeitos com os recursos tecnológicos para contar uma trajetória; sem deixar de solicitar a memória do que somos e as nossas experiências anteriores em permanente diálogo com o outro e com o mundo. Nesse sentido, as narrativas digitais também são escrituras de si que podem oportunizar, conforme Almeida e Valente (2012), a tomada de consciência sobre a própria transformação do sujeito durante a aprendizagem, levando-o a abrir-se ao registro metódico de descrever tantos as histórias quanto as reflexões sobre elas para dar sentido à experiência. Assim, ao narrarem os seus percursos, ao recontarem suas trajetórias por meio das múltiplas linguagens próprias das TDIC e (re)acessar essas histórias também por meio de recursos multimidiáticos, os sujeitos podem desempenhar, simultaneamente, o papel de atores e de investigadores de suas próprias vidas.

Utilizadas em contextos educacionais como elementos do currículo pela ação docente e discente, como histórias condensadoras da experiência sempre única de aprendizagem de cada sujeito, essas narrativas podem alterar o próprio processo de aprendizagem do sujeito incentivando movimentos de reflexão e depuração do conhecimento em um movimento espiral (VALENTE, 2005). Assim, a narrativa digital voltada ao percurso de aprendizagem estaria prenhe de uma tomada de consciência, pelo sujeito-autor, sobre o próprio conhecimento, o processo individual de aprendizagem e as transformações daí decorrentes e cujos efeitos já poderiam ser sentidos durante o processo narrativo/formativo dando-lhe novos rumos.

Se for produzida e compartilhada ainda durante o percurso de aprendizagem e não somente depois de sua conclusão, a narrativa digital pode contribuir para o processo emancipatório do sujeito na medida em que permite a percepção mais clara de seu lugar na cultura (pelo diálogo com o outro e com o contexto) - conforme refere Bruner (1998; 2001) e das temporalidades da vida e do aprender (BIANCHETTI; THIESSEN, 2014).

Ricoeur (1994) postula o caráter narrativo de nossa identidade no tempo afirmando que nossa existência não pode ser separada do modo como nos damos conta de nós mesmos e é 
contando nossas próprias histórias que nos conferimos uma identidade. Todo esse movimento é atravessado pela temporalidade. Conforme Ricoeur (1994, p. 15-16):

O mundo exibido por qualquer obra narrativa é sempre um mundo temporal. [...] o tempo torna-se tempo humano na medida em que está articulado de modo narrativo: em compensação, a narrativa é significativa na medida em que esboça os traços da experiência temporal. [...] É inegável que a tese apresenta um caráter circular. [...] o círculo entre narratividade e temporalidade não é um círculo vicioso, mas um círculo saudável, cujas duas metades se reforçam mutuamente.

Assim, a narrativa digital do processo de aprendizagem coloca em ação e articula o caráter temporal da própria existência humana (pessoal e social) e da produção do conhecimento científico - articulando-se, mais uma vez, à perspectiva da alfabetização científica. Nesse tipo de narrativa, as lembranças e reflexões podem ser apresentadas conforme a temporalidade da experiência subjetiva da aprendizagem (não necessariamente pelo tempo cronológico), e nesse processo os sujeitos vivenciam o caráter tridimensional do tempo narrativo, em que passado, presente e futuro se imbricam (RICOEUR, 1994) - o que pode ser representado mais facilmente com o uso de múltiplas linguagens e mídias associadas para construir o enredo da história.

Dessa forma, a "diacronicidade narrativa" proposta por Bruner (1991) ganha novos contornos e potencializa a percepção de que o "[...] tempo envolvido [na narrativa], como notou Paul Ricoeur, é o 'tempo humano' e não o tempo abstrato ou o tempo do 'relógio'” (BRUNER, 1991, p. 6). Pelo uso dos recursos tecnológicos nas narrativas digitais, a dualidade entre tempo cronológico e tempo fenomenológico, entre chronos e kairós, se evidencia promovendo (por meio de links e outros recursos hipermidiáticos) a percepção de que "O presente é a abertura de um horizonte temporal. Por isso, o passado e o futuro ainda que nossos só são significativos desde o horizonte aberto no presente" (LARROSA, 2004, p. 15, tradução nossa).

Nesse sentido, o caráter temporal da experiência humana de aprender articula-se pela narrativa e as TDIC contribuem para a percepção dessa articulação assim como para a "composicionalidade hermenêutica" (também proposta por Bruner, 1991) na medida em que permitem uma maior porosidade entre os sentidos atribuídos à narrativa e negociados entre autor e leitor. Essa porosidade decorre especialmente das múltiplas possibilidades de aproximação e diálogo abertas pelas tecnologias na narrativa digital e fortalece a compreensão 
de que "[...] nenhuma história possui uma única interpretação exclusiva. Seus significados são, a princípio, múltiplos" (BRUNER, 2001, p. 132).

Assim, por suas características, as TDIC contribuem para promover a transformação da narrativa tradicional em um "[...] instrumento da mente no lugar da produção de significado" na medida em que podemos “[...] lê-la, produzi-la, analisá-la, entender seus mecanismos, sentir seus usos, discuti-la" (BRUNER, 2001, p. 45) e refazê-la com apoio das tecnologias de nosso tempo.

\section{NARRATIVAS DIGITAIS E EXPERIÊNCIA: DIÁlOGOS POSSÍVEIS E IMPLICAÇÕES EDUCACIONAIS}

O multifacetado conceito de "experiência" foi discutido de Descartes a Dewey com os mais diferentes enfoques e recortes teóricos. Neste segundo tópico, dentre os diversos contornos possíveis, o desenho conceitual de "experiência" que apresento e entendo oferecer ricas possibilidades de diálogo com a narrativa digital constitui-se especialmente a partir de Heidegger (2003) e Larrosa (2002; 2004; 2011b), mas traz também as construções teóricas de Passeggi (2011), Freire (1982, 1996, 2014) e Kearney (2012).

Larrosa (2011b) nos propõe "des-empirizar" o conceito de experiência dissociando-o da ideia de experimento. Para tanto, sugere alguns princípios que fundamentam o conceito: a) singularidade, irrepetibilidade, pluralidade; b) incerteza, liberdade, talvez; c) paixão. Pelo princípio da singularidade, o autor ratifica a ideia de que a experiência não é da instância do geral (da generalização), mas também não é do individual ou do particular. É do singular. Em outras palavras, é sempre diferente para cada sujeito e é também irrepetível para o mesmo sujeito; ou seja, minha experiência é diferente da experiência do outro, mas também cada experiência minha é única e irrepetível para mim (HEIDEGGER, 2003).

O princípio da incerteza, da liberdade e do talvez remete "[...] à abertura do possível, mas também do impossível, do surpreendente, do que não pode ser [...] a experiência é um talvez. [...] é o lugar da liberdade" (LARROSA, 2011b, p. 19). Esse princípio associa a experiência à aventura, ao perigo, ao risco - presentes na própria raiz 'per' de 'provar' (experieri) e de 'perigo' (periculum) - e, de certa forma, nos leva ao princípio seguinte: o da paixão. 
Pelo princípio da paixão, Larrosa (2011a) coloca que a experiência não está ao lado da ação, ou da prática; não é intencional. Ou seja, ao realizar uma ação, ela não necessariamente se constituirá como uma experiência para o sujeito, ainda que ele deseje isso. A experiência só se dará na medida em que o sujeito for atravessado, derrubado, padecer. Larrosa (2002, p. 26) explica:

No padecer não se é ativo, porém, tampouco se é simplesmente passivo. $\mathrm{O}$ sujeito passional [da experiência] não é agente, mas paciente, mas há na paixão um assumir os padecimentos, como um viver, ou experimentar, ou suportar, ou aceitar, ou assumir o padecer que não tem nada que ver com a mera passividade, como se o sujeito passional fizesse algo ao assumir sua paixão.

A produção de uma narrativa pode configurar-se como experiência, uma vez que é sempre singular, única, irrepetível. Ainda que narre sempre a sua própria história, o sujeito o fará de diferentes maneiras e por diferentes perspectivas (mais próximas do real ou mais próximas do imaginado) conforme o olhar, o tempo histórico, o viés psicológico, o momento de vida, amadurecimento e aprendizagem em que se encontra. E no que tange à narrativa digital, essa experiência pode ganhar ainda outros contornos decorrentes das próprias características dessas narrativas já apresentadas no tópico anterior a partir de Paul (2007), Xu, Park e Bak (2011) dentre outros autores.

Por essa razão, a narrativa de si sintetiza uma perspectiva, uma representação da inserção do sujeito no mundo por meio da leitura e da escrita enquanto construtos socioculturais. Assim, "Nossa exposição às novas possibilidades de ser reconfigura nosso estarno-mundo cotidiano. De modo que quando retornamos do mundo narrado para o mundo real, nossa sensibilidade é enriquecida e amplificada em importantes aspectos" (KEARNEY, 2012, p. 414). Nessa direção, o narrar ainda poderia estar associado à experiência, de educandos e educadores, proposta por Freire (1982), a qual está “[...] fortemente referenciada como locus das relações dinâmicas que vinculam linguagem e realidade no exercício da compreensão do contexto da prática" (MOLINA, 2008, p. 186). Nas narrativas digitais, essa experiência mesma do narrar-se é alterada (e pode ser até enriquecida) pelas múltiplas linguagens das mídias conforme apontam Santaella (2007) e Chatier (1999) - que abrem novas possibilidades de representação do pensamento e do mundo além do texto escrito.

A escritura de si, por sua vez, é sempre uma abertura ao inesperado que vem com o escrever, seja esse ato realizado por mídias digitais ou não (MACHADO, 2000; RODRIGUES, 
2011). Ainda que saibamos o que desejamos narrar no início, o movimento mesmo da escrita (ampliada pelas possibilidades abertas pelas mídias digitais) nos leva, quando nos entregamos a ele (com paixão), a caminhos desconhecidos. O desvendar desses caminhos é o que pode nos atravessar no sentido da experiência larrosiana. Ao mesmo tempo, o mostrar-se pela escritura, pela imagem, pelo som etc. (próprios das multiplicidade semiótica das narrativas digitais) é um desafio perigoso, expõe ainda mais o sujeito, coloca-o à mercê (de si mesmo, do outro, do mundo) - assim como o sujeito passional e o autor, que mesmo expostos e vulneráveis, colocam-se nessa posição e assumem-na em suas consequências. Tanto quanto a narrativa de si, a experiência não é o caminho para uma meta ou um fim que se conhece a priori, mas é "[...] uma abertura para o desconhecido, para o que não é possível antecipar” (LARROSA, 2011b, p. 14). E não é também essa uma peculiaridade do aprender?

Considerando que experiência e narrativa se entrelaçam tornando-se parte da expressão da vida do sujeito (CUNHA, 1997), no caso das situações de aprendizagem, é possível inferir que as narrativas digitais possam, quando utilizadas adequadamente e inseridas organicamente nas práticas curriculares, contribuir para a construção de outros significados para o aprender e o aprendido ampliando-lhes os sentidos e produzindo experiências (no sentido larrosiano). Nesse processo, são centrais a escuta dos educandos (pela leitura de suas narrativas), o diálogo intersubjetivo e contextualizado (pelo compartilhamento das narrativas, facilitado pela midiatização das tecnologias digitais) e a aventura criadora (pela ação de escrever e narrar-se) - como há tempos Freire (1996) já nos alertava propondo que a posição de educadores e educandos no mundo (e relativamente aos conhecimentos produzidos e compartilhados nesse mundo) não seja a de quem não tem nada a ver com isso. Antes, precisa ser "[...] a de quem nele se insere. É a posição de quem luta para não ser apenas objeto, mas sujeito também da História" (FREIRE, 1996, p. 54, grifo do autor).

Por esse viés, o ato de usar a narrativa digital como recurso pedagógico reconhece a aprendizagem como processo e concretiza esse reconhecimento colocando em foco a experiência de aprender, valorizando o “[...] conhecimento relacional [...] 'molhado' de intuições, adivinhações, desejos, aspirações, dúvidas, medo, a que não falta, porém, razão também" (FREIRE, 2014, p. 71). As possibilidades abertas pelas mídias digitais também podem favorecer esse conhecimento relacional em função de sua fluidez e da oportunidade de refazer com certa facilidade a narrativa o longo do processo de aprendizagem e das interações com os outros. 
Ao selecionar e narrar aquilo que o atravessou, tombou, desestabilizou durante a aprendizagem de um conceito científico, por exemplo, o sujeito pode refletir e avançar (ou mesmo recuar) porque passa a construir e compreender o que se passou com ele em diálogo com o outro, com o conhecimento e com o mundo pela via da narrativa construída sobre e com o apoio dos suportes tecnológicos de nosso tempo. Assim, “[...] podemos prontamente aceitar que a narrativa seja um processo fazedor do mundo assim como um processo revelador do mundo" (KEARNEY, 2012, p. 423). Nesse 'fazer-revelar' temos também o sentido heideggeriano e larrosiano de experiência como "[...] o que nos passa, o que nos acontece, o que nos toca. Não o que se passa, o que acontece, ou o que toca” (LARROSA, 2002, p. 21, grifos nossos). Ou seja, a narrativa coloca o sujeito em relação consigo, com os outros, com o objeto do conhecimento assumindo-se enquanto construtor da realidade da qual faz parte e refletindo sobre ela para atuar novamente nela num movimento dialético de práxis que coloca em ação “[...] uma das tarefas mais importantes da prática educativo-crítica [que] é propiciar as condições para que os educandos [...] ensaiem a experiência profunda de assumir-se" (FREIRE, 1996, p. 41) - e novamente parecem claras as possibilidades de construção de experiências curriculares genuínas abertas pelas narrativas digitais em diferentes contextos educacionais.

Em outras palavras, o exercício de narrar o processo de aprendizagem e narrar-se por esse processo leva o sujeito a estabelecer diferenças entre o que aconteceu e o que lhe aconteceu. Durante situações de ensinar e aprender muitas coisas acontecem, mas às vezes poucas coisas (ou mesmo nenhuma) acontece ao sujeito no sentido de fazê-lo viver uma autêntica experiência de aprendizagem. Ao produzir uma narrativa desse processo, é preciso fazer escolhas, refletir e eleger o que foi, de fato, constitutivo da experiência. Esta última, por sua vez, sempre vinculada à subjetividade posta em relação com a objetividade e a alteridade.

Nesse movimento de externar o 'eu aprendente' em suas múltiplas facetas representadas por uma diversidade de recursos semióticos, a narrativa digital de aprendizagem pode tornarse, ela mesma, uma experiência: por um lado, porque coloca o sujeito diante do outro e em diálogo com o outro; e esse diálogo pode alterar as escolhas feitas e a própria experiência de quem narra. Por outro lado, porque a relação reflexiva do sujeito no processo de escrita e com o produto dessa escrita de si reverbera também internamente, implicando no que esse sujeito é; e tem, por isso mesmo, uma dimensão transformadora, que o faz outro do que é, que o modifica num efeito bumerangue (RODRIGUES, 2012). Assim, “As histórias alteram nossas vidas 
quando retornamos do texto para a ação" (KEARNEY, 2012, p. 429) e, se nos alteram de alguma forma, é porque nos atravessaram, nos tombaram.

Passeggi (2011) auxilia-nos a compreender esse movimento ao recuperar a etimologia do termo experiência (do latim, experientialae), cujo sentido indica prova, ensaio, tentativa. A autora lembra que esse sentido implica capacidade de entendimento, por parte do sujeito, da diferença entre o que acontece e o que lhe acontece. Os termos Erlebnis e Erfahrung também contribuem para a compreensão da experiência e de sua relação com a narrativa:

[...] Erlebnis e Erfahrung, equivalentes de experiência em alemão, começamos a dar uma atenção especial à ressignificação da experiência e a melhor problematizá-la em nossos estudos. Erlebnis traduz-se, geralmente, por 'experiência vivida' ou 'vivência', entendida como uma experiência mais imediata, pré-reflexiva e pessoal; Erfahrung associa-se a impressões sensoriais e ao entendimento cognitivo, que integra a experiência num todo narrativo e num processo de aprendizagem. A palavra Erfahrung compõe-se de Farht (viagem) e pode ser associada a Gefahr (perigo) (PASSEGGI, 2011, p. 148).

A estreita ligação entre narrativa e experiência parece estar no exercício cognitivo (exigido pela narrativa e potencializado pelas mídias digitais e suas características) de selecionar, juntar, ordenar, organizar e atribuir sentido aos elementos do vivido que constituem a experiência porque atravessaram o sujeito - o que também pode ser entendido como um processo de criação da própria realidade e que traz “[...] a função comum da narrativa enquanto poiesis: ou seja, um modo de fazer de nossas vidas histórias de vida" (KEARNEY, 2012, p. 412). Esse exercício mostra a dinâmica de relações necessárias à constituição da experiência, traduzidas por Larrosa (2002, 2004, 2011a), a partir da análise da expressão-chave "o que me passa”, em algumas dimensões (representadas na Figura 1):

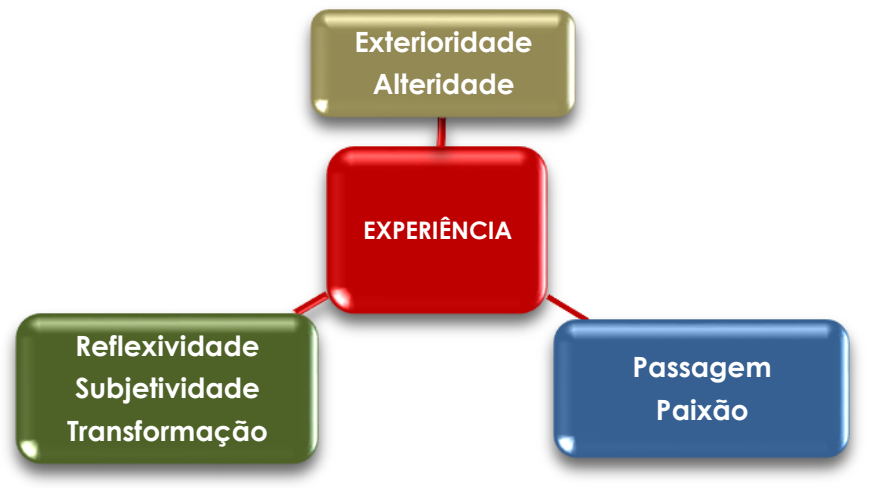

Figura 1 - Dimensões da Experiência Fonte: Adaptado de Larrosa (2011b) 
A dimensão exterioridade/alteridade diz respeito, na expressão-chave, a "o que", ao que é exterior ao sujeito. Reflexividade/subjetividade/transformação relaciona-se à conjunção "me" e passagem/paixão é associada, pelo autor, à palavra "passa". As três dimensões não são isoladas, mas coexistem em relação umas às outras e articulam-se entre si constituindo a experiência.

Partindo das associações de Larrosa (op. cit.), podemos olhar para essas dimensões pensando a narrativa digital enquanto potencial de experiência em situações de aprendizagem. Nessa situação, a exterioridade/alteridade estaria representada tanto pelo objeto do conhecimento (o conteúdo - 'o que') quanto pelas relações com o outro (colegas, professores etc. - 'quem') e com o mundo no processo de aprender; na dimensão reflexividade/subjetividade/transformação estaria o sujeito que narra seu processo representando-o por meio da criação e recriação de elementos multimidiáticos que traduzem, mas também constituem a sua experiência singular de aprendizagem ('me') em determinado contexto; e a paixão/passagem seria representada pela entrega à descoberta/construção e ao movimento de aprender (que nos atravessa, nos 'passa') cujos caminhos são sempre desconhecidos a priori.

Nesse sentido, podemos pensar que o sujeito da experiência narrativa tanto descobre quanto cria, num movimento de invenção de si, do outro e do mundo que permite compreender/vivenciar a experiência de aprendizagem e também, como refere Rodrigues (2017), a experiência autoral.

Mimesis é invenção no sentido original do termo: invenire significa tanto descobrir como criar, ou seja, revelar aquilo que já estava ali à luz do que ainda não é (mas é potencialmente). É o poder, em resumo, de recriar mundos atuais na forma de mundos possíveis. Este poder de recriação mimética mantém uma conexão entre ficção e vida, ao mesmo tempo em que reconhece a diferença entre elas. A vida pode ser adequadamente compreendida apenas ao ser recontada mimeticamente através das histórias (KEARNEY, 2012, p. 414).

Considerando essas dimensões, concordo com Passeggi (2011) sobre a importância da noção de consciência histórica para compreendermos a experiência formativa do aprender. "Entendemos que ela só se justifica se permitir à pessoa que narra compreender a historicidade de suas aprendizagens e construir uma imagem de si como sujeito histórico, situado em seu tempo" (PASSEGGI, 2011, p. 149). Dessa maneira, a autora argumenta que a experiência se constitui “[...] nessa relação entre o que nos acontece e a significação que atribuímos ao que 
nos afetou. Isso se faz mediante o ato de dizer, de narrar, (re)interpretar" (PASSEGGI, 2011, p. 149). Desde esse ponto de vista, vivência e experiência também podem ser diferenciadas, como propõe Fantin (2012) a partir das reflexões de Walter Benjamin (1996): "Vivência (que se refere à vida do indivíduo particular, na sua preciosidade e solidão) em oposição à Experiência (que se refere ao vivido, refletido, narrado e compartilhado)" (FANTIN, 2012, p. 295). Nessa diferenciação também podemos verificar a presença das dimensões propostas por Larrosa (2011b) e compreender a proposição de Benjamin (1996) que, há muito, já apontava para a rarefação de experiências que caracteriza o mundo contemporâneo.

Consoante a esse apontamento, Larrosa $(2002 ;$ 2004) afirma que nunca se passaram tantas coisas, mas a experiência é cada vez mais rara. $\mathrm{O}$ autor sugere algumas razões para isso: 1) o excesso de informação; 2) o excesso e o imperativo da opinião, que se unindo ao excesso de informação gera o que Benjamin denomina "periodismo"; 3) a escassez de tempo e a rapidez do mundo; 4) o excesso de trabalho. Todos esses elementos nos impedem, segundo Larrosa, de parar e nos fazem estar sempre mobilizados.

E, por não podermos parar, nada nos acontece. A experiência, a possibilidade de que algo nos aconteça ou nos toque, requer um gesto de interrupção [...]: requer parar para pensar, parar para olhar, parar para escutar, pensar mais devagar, olhar mais devagar, e escutar mais devagar; parar para sentir, sentir mais devagar, demorar-se nos detalhes, suspender a opinião, suspender o juízo, suspender a vontade, suspender o automatismo da ação, cultivar a atenção e a delicadeza, abrir os olhos e os ouvidos, falar sobre o que nos acontece, aprender a lentidão, escutar os outros, cultivar a arte do encontro, calar muito, ter paciência e dar-se tempo e espaço (LARROSA, 2002, p. 24).

Entendo que a produção de narrativas digitais sobre o processo de aprendizagem durante o desenrolar do próprio processo de aprender pode abrir espaço, em diferentes contextos educacionais, para essa interrupção a que se refere Larrosa. Incorporando as linguagens, mídias e possibilidades tecnológicas e dialógicas da contemporaneidade, as narrativas digitais permitem usar recursos de nosso tempo a favor de que o sujeito possa 'parar' para olhar para si e para o seu processo construção do conhecimento quando se põe a narrá-lo, mas também quando ouve, reflete e aprende com a narração do outro. Essa escritura de si pode “desautomatizar" as ações e convidar ao cuidado com os detalhes ao mesmo tempo em que permite ao sujeito deixar-se sentir, olhar, pensar e encontrar - humanizar-se. O próprio digital (apesar da rapidez e do excesso de informações que lhe são peculiares) pode se configurar, na narrativa digital, como elemento incentivador para o sujeito parar e perceber a experiência a 
fim de contá-la por meio de diferentes recursos (além da escrita) que dizem aos nossos olhos e ouvidos. Trata-se, assim, da “experiência formativa entretecida aos potenciais pedagógicos dos dispositivos tecnológicos" (MACEDO 5 , 2015).

\section{CONSIDERAÇÕES FINAIS}

Este texto se propôs a apresentar uma reflexão teórica sobre o conceito de narrativa digital em diálogo com o conceito de experiência em Heidegger (2003) e Larrosa (2002; 2004; 2011a; 2011b) e suas possíveis implicações para a Educação em uma perspectiva humanista. Como conclusões, o estudo mostrou que a midiatização da narrativa pode contribuir para o trabalho humano de educar e educar-se na medida em que maximiza os efeitos reflexivos e de tomada de consciência já próprios das narrativas tradicionais devido aos elementos constitutivos das narrativas digitais e próprios das ferramentas multi e hipermidiáticas pelas quais elas são construídas. Além disso, a facilidade de reelaboração permanente da narrativa (decorrente também das características da digitalidade) possibilita e pode até mesmo estimular a reflexão constante sobre a experiência e a ressignificação desta. O caráter digital da narrativa pode, ainda, auxiliar a construção de novas formas de aprender, de ensinar e de construir o currículo nos múltiplos espaços educacionais e níveis de ensino, uma vez que as mídias digitais e os hiperlinks propiciam a abertura do currículo a diferentes contextos - que podem compor a narrativa digital como elementos de constituição da experiência. Da mesma forma que as diferentes linguagens (audio, imagens, animações, textos escritos etc.) possíveis nas narrativas digitais ampliam as formas pelas quais o conhecimento pode ser acessado e, principalmente, representado pelos sujeitos aprendentes.

As narrativas digitais podem, também, auxiliar a construção de contextos formativos em rede nos quais a colaboração, a coautoria e a coaprendizagem sejam incentivadas pela negociação de sentidos entre os sujeitos envolvidos e pela ressignificação dos conhecimentos e dos conteúdos curriculares desde a experiência contextualizada desses sujeitos inseridos na cultura e em diálogo com o outro e o mundo. Essas redes colaborativas são facilitadas por ferramentas digitais como wiki e outros recursos de edição coletiva, drives compartilhados e as próprias redes sociais. Por meio dessas ferramentas, as narrativas digitais podem ser construídas em conjunto pelos sujeitos envolvidos no processo de aprender ampliando a colaboração, o 
exercício do diálogo e da escuta, a reflexão sobre a própria experiência e sobre a do outro - o que amplia as possibilidades de realização de uma educação humanista.

Assim, as narrativas digitais, quando utilizadas como elementos curriculares que abrem espaço para o diálogo intersubjetivo materializado por meio de diferentes linguagens, podem contribuir para que os sujeitos percebam as possibilidades de construção de um conhecimento 'encarnado', humanizado e humanizador - pelo qual e no qual dialogam objetividade e subjetividade, individual e coletivo, conhecimentos comuns e conhecimentos científicos, saberes e fazeres numa “ecologia de saberes" (SANTOS, 2007; 2010a; 2010b).

Nesse sentido, essas narrativas poderiam ainda ser um caminho, no currículo, para o que Bauman (2008) e Goodson (2007) apontam como sendo a "aprendizagem terciária" e que "[...] diz respeito a viver sem hábitos ou aprendizagens rotineiras, a romper com as prescrições predeterminadas do currículo, a voltar-se para a definição, apropriação e narrativa contínua de seu próprio currículo" (GOODSON, 2007, p. 241). A partir dessa ideia, o autor nos convida a “[...] mudar de um currículo prescritivo para um currículo como identidade narrativa; de uma aprendizagem cognitiva prescrita para uma aprendizagem narrativa de gerenciamento da vida" (GOODSON, 2007, p. 242). Tendo em horizonte esse tipo de currículo, as narrativas digitais podem ser um terreno fértil para darmos início à sua construção, uma vez que podem ser desenvolvidas tendo como base os conteúdos curriculares prescritos, mas articulando-os à história dos sujeitos, ao lugar social que ocupam e situando as aprendizagens nesse contexto enquanto "aprendizagens narrativas".

Se a educação está hoje inserida em um mundo de cultura digital, está também mergulhada nas TDIC, e por isso é preciso pensar a tecnologia como ferramenta cognitiva (JONASSEN, 2007), como instrumento sociocultural de nosso tempo, para incorporá-la significativamente (e não apenas do ponto de vista da instrumentalização) à prática pedagógica, integrá-la ao currículo, envolvê-la na ação educativa. É necessário, para isso, superar posturas ingênuas e salvacionistas, mas também medrosas e demonizadoras, assumindo sempre uma posição crítica, de reflexão e questionamento numa práxis contextualizada para uma educação transformadora e humanizadora. 


\section{REFERÊNCIAS}

ALMEIDA, Maria Elizabeth Bianconcini de. Narrativas digitais. In: MILL, Daniel (Org.). Dicionário Crítico de educação e tecnologias e de educação a distância. Campinas/SP: Papirus, 2018. p. 475-479.

ALMEIDA, Maria Elizabeth Bianconcini de; VALENTE, José Armando. Integração currículo e tecnologias e a produção de narrativas digitais. Currículo sem fronteiras, v. 12, n. 3, p. 5782, set/dez. 2012. Disponível em:

http://www.curriculosemfronteiras.org/vol12iss3articles/almeida-valente.pdf. Acesso em: 27 mar. 2020.

ASSMANN, Hugo. A metamorfose do aprender na sociedade da informação. Ciência da Informação, Brasília, v. 29, n. 2, p. 7-15, maio/ago. 2000. Disponível em: http://www.scielo.br/pdf/ci/v29n2/a02v29n2. Acesso em: 12 mar. 2020.

BAUMAN, Zigmunt. A sociedade individualizada: vidas contadas e histórias vividas. Trad. José Gradel. Rio de Janeiro: Zahar, 2008.

BIANCHETTI, Lucídio; THIESEN, Juares da Silva. O lugar das utopias e distopias no debate social e pedagógico na atualidade. In: BIANCHETTI, Lucídio; THIESEN, Juares da Silva. (Orgs.). Utopias e distopias na modernidade: educadores em diálogo com T. Morus, F. Bacon, J. Bentham, A. Huxley e G. Orwell. Ijuí: Ed. UNIJUÍ, 2014. p. 21-42.

BENJAMIN, Walter. Obras Escolhidas I - Magia e técnica, arte e política: ensaios sobre a literatura e história da cultura. 7. ed. São Paulo: Brasiliense, 1996.

BRUNER, Jerome. A Construção Narrativa da Realidade. Trad. Waldemar Ferreira Netto. Critical Inquiry, vol. 18, n. 1, p. 1-21, 1991. Disponível em: https://www.academia.edu/4598706/BRUNER Jerome.A_constru\%C3\%A7\%C3\%A3o_nar rativa_da_realidade. Acesso em: 28 nov. 2019.

BRUNER, Jerome. Atos de significaçãa. Porto Alegre: Artes Médicas, 1998.

BRUNER, Jerome. A cultura da educação. Porto Alegre: Artmed, 2001.

CARVALHO, Gracinda Souza de. As Histórias Digitais: Narrativas no Século XXI. O Software Movie Maker como Recurso Procedimental para a Construção de Narrações. Orientadora: Vera Lucia Marinelli. 2008. 197 f. Dissertação (Mestrado em Educação) Universidade de São Paulo, São Paulo. 2008. Disponível em: http://www.teses.usp.br/teses/disponiveis/48/48134/tde-27082010104511/publico/Gracinda_Souza_de_Carvalho.pdf. Acesso em: 30 nov. 2019.

CHARTIER, Roger. A aventura do livro: do leitor ao navegador. São Paulo: UNESP, 1999.

CLARKE, Robert; ADAM, Andrea. Digital Storytelling in Australia: Academic Perspectives and Reflections. Arts and Humanities in Higher Education, v. 11, n. 1-2, p. 157-176, feb./apr. 2012. Disponível em: eric.ed.gov/?id=EJ955497. Acesso em: 12 fev. 2020.

COSTA, Sérgio Roberto. Dicionário de gêneros textuais. 2. ed. Belo Horizonte: Autêntica, 2009. 
CUNHA, Maria Isabel. Conta-me agora! As narrativas como alternativas pedagógicas na pesquisa e no ensino. Revista da Faculdade de Educação, v. 23, n. 1/2, p. 185-195, jan./dez. 1997. Disponível em: http://www.revistas.usp.br/rfe/article/view/59596/62695. Acesso em: 30 mar. 2020.

FISCHER, Rosa Maria Bueno. Mídia, máquinas de imagens e práticas pedagógicas. Revista Brasileira de Educação, v. 12, n. 35, p. 290-299, maio/ago. 2007. Disponível em: link. https://www.scielo.br/pdf/rbedu/v12n35/a09v1235.pdf. Acesso em: 10 jun. 2020.

FREIRE, Paulo. Pedagogia dos sonhos possíveis. São Paulo: Editora Paz e Terra, 2014.

FREIRE, Paulo. A importância do ato de ler: em três artigos que se completam. São Paulo: Cortez, 1982.

FREIRE, Paulo. Pedagogia da autonomia: saberes necessários à prática educativa. 34. ed. São Paulo: Paz e Terra, 1996.

GOODSON, Ivor. Currículo, narrativa e futuro social. Revista Brasileira de Educação, v. 12, p. 241-252, mai/ago. 2007. Disponível em:

https://www.scielo.br/pdf/rbedu/v12n35/a05v1235.pdf. Acesso em: 10 jun. 2020.

HEIDEGGER, Martin. A caminho da linguagem. Trad. Márcia Sá Cavalcante Schuback. Petrópolis/RJ: Vozes, 2013.

JONASSEN, David. Computadores, ferramentas cognitivas: desenvolver o pensamento crítico nas escolas. Porto: Editora Porto, 2007.

KEARNEY, Richard. Narrativa. Educação \& Realidade, v. 37, n. 2, p. 409-438, maio/ago. 2012. Disponível em: http://www.redalyc.org/articulo.oa?id=317227324006. Acesso em: 26 mar. 2020.

LARROSA, Jorge. Notas sobre a experiência e o saber da experiência. Revista Brasileira de Educação, Rio de Janeiro, n. 19, p. 20-28, jan./abr. 2002. Disponível em:

http://www.scielo.br/scielo.php?script=sci_arttext\&pid=S1413-

24782002000100003\&lng=pt\&nrm=iso. Acesso em: 20 mar. 2020.

LARROSA, Jorge. Notas sobre narrativa e identidade (a modo de presentación). In: ABRAHÃO, Maria Helena Menna Barreto (Org.). A aventura (auto)biográfica: teoria e empiria. Porto Alegre: EDIPUCRS, 2004. p. 11-22.

LARROSA, Jorge. Tecnologias do Eu e Educação. In: SILVA, Tomás Tadeu da (Org.). O sujeito da educação: estudos foucaultianos. Petrópolis/RJ: Vozes, 2011a. p. 35-86.

LARROSA, Jorge. Experiência e alteridade em Educação. Revista Reflexão e Ação, Santa Cruz do Sul, v. 19, n. 2, p. 04-27, jul.dez. 2011b. Disponível em:

https://online.unisc.br/seer/index.php/reflex/article/download/2444/1898. Acesso em: 04 fev. 2020.

LIMA JUNIOR, Arnaud Soares de. Tecnologias inteligentes e educação: currículo hipertextual. Rio de Janeiro: Quarter; Juazeiro/BA: FUNDESF, 2005. 
MACEDO, Roberto Sidinei. Currículo no século XXI. In: IV SEMINÁRIO WEB CURRÍCULO/XII ENCONTRO DE PESQUISADORES EM CURRÍCULO, 2015, São Paulo.

MACHADO, Ana Maria Netto. Presença e implicações da noção de escrita na obra de Jacques Lacan. 2. ed. Ijuí: Ed. UNIJUÍ, 2000.

MARCUSCHI, Luiz Antônio. Gêneros textuais emergente no contexto da tecnologia digital. In: MARCUSCHI, Luiz Antônio; XAVIER, Antônio Carlos (Orgs.). Hipertexto e gêneros textuais: novas formas de construção de sentido. 3. ed. São Paulo: Cortez, 2010. p. 15-80.

MARTINO, Luís Mauro de Sá. Teoria das Mídias Digitais: linguagens, ambientes, redes. 2. ed. Petrópolis/RJ: Vozes, 2015.

MOLINA, Roseane Kreusburg. Experiência. In: STREK, Danilo R. Streck; REDIN, Euclides; ZITKOSKI, Jaime José (Orgs.). Dicionário Paulo Freire. Belo Horizonte: Autêntica, 2008. p. 186-187.

MURRAY, Janet H. Hamlet no holodeck: o futuro da narrativa no ciberespaço. Trad. Elissa Khoury Daher. São Paulo: Itaú Cultural/UNESP, 2003.

NAZAR, Teresa. O escrito da escrita. In: MARIANI, Bethania (Org.). A escrita e os escritos: reflexões em análise do discurso e psicanálise. São Carlos: Claraluz, 2006. p. 159-174.

PASSEGGI, Maria da Conceição. A experiência em formação. Educação, v. 34, n. 2, p. 147156, maio-ago. 2011. Disponível em: http://www.redalyc.org/articulo.oa?id=84819058004. Acesso em: 26 mar. 2020.

PAUL, Nora. Elementos das narrativas digitais. In: FERRARI, Pollyana (Org.) Hipertexto, hipermídia: as novas ferramentas da comunicação digital. São Paulo: Contexto, 2007. p. 121140.

RICOEUR, Paul. Tempo e Narrativa (Tomo I). Trad. Constança M. Cesar. Campinas/SP: Papirus, 1994.

RICOEUR, Paul. Percurso do Reconhecimento. São Paulo: Loyola, 2006.

ROBIN, Bernard. R. Digital Storytelling: a powerful technology toll for the $21^{\text {st }}$ century classroom. Theory Into Pratice, n. 47, p. 220-228, 2008. Disponível em:

eric.ed.gov/?id=EJ799668. Acesso em: 20 jul. 2019.

RODRIGUES, Alessandra. Escrita e autoria: entre histórias, memórias e descobertas. Campinas/SP: Mercado de Letras, 2011.

RODRIGUES, Alessandra. Efeito bumerangue: considerações acerca das condições de construção de autoria. In: Machado, Ana Maria Netto (Org.). Toc, toc, toc, eu quero entrar!: conhecimento e reconhecimento de egressos do stricto sensu e transformação social Florianópolis: DIOESC, 2012. p. 65-80.

RODRIGUES, Alessandra. Narrativas digitais, autoria e currículo na formação de professores mediada pelas tecnologias: uma narrativa-tese. Orientadora: Maria Elizabeth 
Bianconcini de Almeida. 2017. 274 f. Tese (Doutorado em Educação: Currículo) - Pontifícia Universidade Católica de São Paulo, São Paulo, 2017. Disponível em: https://tede2.pucsp.br/handle/handle/20196. Acesso em: 30 mar. 2020

RODRIGUES, Alessandra. Mídias, efeitos de sentido e práticas de leitura e escrita: o que nos contam as narrativas digitais? Leitura: Teoria \& Prática, v. 37, n. 75, p. 101-113, 2019a. Disponível em: https://ltp.emnuvens.com.br/ltp/article/view/750. Acesso em: 30 mar. 2020.

RODRIGUES, Alessandra. A autoria e a narrativa digital na formação de professores de Ciências mediada pelas tecnologias: entrelaçando possibilidades pela escritura de si. Revista Educação e Cultura Contemporânea, v. 16, v. 43, p. 276-304, 2019b. Disponível em: http://revistaadmmade.estacio.br/index.php/reeduc/article/viewArticle/5423. Acesso em: 30 mar. 2020.

RODRIGUES, Alessandra; GONÇALVES, Lina Maria. Narrativas digitais na formação de professores: da memória, do registro e do discurso emergem posturas e experiências. Revista Contexto \& Educação, ano 29, n.94, p. 212-237, set./dez. 2014. Disponível em: https://www.revistas.unijui.edu.br/index.php/contextoeducacao/article/view/3979/467. Acesso em: 19 dez. 2019.

ROTHER, Edna Terezinha. Editorial. Acta Paulista Enfermagem, v. 20, n. 2, vi, 2007. Disponível em: http://www.scielo.br/pdf/ape/v20n2/a01v20n2.pdf. Acesso em: 27 mar. 2020.

SANTAELLA, Lúcia. Linguagens líquidas na era da modernidade. São Paulo: Paulus, 2007.

SANTOS, Boaventura de Sousa. Renovar a teoria crítica e reinventar a emancipação social. São Paulo: Boitempo, 2007.

SANTOS, Boaventura de Sousa. Um discurso sobre as ciências. 7. ed. São Paulo: Cortez, 2010a.

SANTOS, Boaventura de Sousa. Para além do pensamento abissal: das linhas globais a uma ecologia de saberes. In: SANTOS, Boaventura de Sousa; MENESES, Maria Paula (Orgs.). Epistemologias do Sul. São Paulo, Cortez, 2010b. p. 31-83.

SKLIAR, Carlos. Escrevendo e lendo sobre a identidade, a diferença e a solidão. Leitura: Teoria \& Prática, v. 34, n. 66, p. 13-29, 2016. Disponível em: https://ltp.emnuvens.com.br/ltp/article/view/444. Acesso em: 10 jun. 2020.

VALENTE, José Armando. A espiral da espiral de aprendizagem: o processo de compreensão do papel das tecnologias de informação e comunicação na educação. 2005. 238 f. Tese (Livre Docência) - Instituto de Artes, Universidade Estadual de Campinas, Campinas/SP, 2005. Disponível em: www.bibliotecadigital.unicamp.br/document/?view=000857072. Acesso em: 16 abr. 2020.

VIEIRA PINTO, Álvaro. O conceito de tecnologia. Rio de Janeiro: Contraponto, 2005.

XU, Yan; PARK, Hyungsung; BAEK, Youngkyun. A New Approach Toward Digital Storytelling: An Activity Focused on Writing Self Efficacy in Virtual Learning Environment. Educational Technology \& Society, v. 14, n. 4, p. 181-191, 2011. Disponível em: 
https://www.researchgate.net/publication/220374689_A_New_Approach_Toward_Digital_St orytelling_An_Activity_Focused_on_Writing_Selfefficacy_in_a_Virtual_Learning_Environment. Acesso em: 17 mar. 2020.

\section{NOTAS}

${ }^{1}$ Agradecimentos ao CNPq pelo apoio financeiro aos estudos que possibilitaram a produção deste artigo.

${ }^{2}$ A opção pelo uso da expressão Tecnologias "Digitais" de Informação e Comunicação tem a intenção de destacar o caráter digital das tecnologias utilizadas para a elaboração e o compartilhamento das narrativas de que trata este estudo. A digitalidade é elemento central que altera de maneira inequívoca as narrativas tradicionais (apenas orais ou escritas). Destacamos que a sigla TDIC vem sendo amplamente utilizada por pesquisadores brasileiros como Maria Elizabeth Bianconcini de Almeida, José Armando Valente, Edméa Santos dentre outros.

${ }^{3}$ A narrativa digital vem sendo utilizada e estudada com diversas nomenclaturas e abordagens: digital storytelling, narrativa multimídia, digital stories, digital narratives. Neste texto optei pela utilização dos termos "narrativa digital" e "digital storytelling" por serem os mais frequentemente utilizados em estudos de viés educacional e pelas principais referências teóricas da pesquisa.

${ }^{4} \mathrm{O}$ uso de termo "interatividade" deve-se à tradução literal do termo utilizado pelos autores: "interactivity". No entanto, o sentido atribuído pelos autores ao termo aproxima-se daquele associado à palavra "interação", em língua portuguesa.

${ }^{5}$ Palestra proferida pelo autor na mesa redonda intitulada "Currículo no século XXI" durante o IV Seminário Web Currículo e o XII Encontro de Pesquisadores em Currículo, de 21 a 23 de setembro de 2015, na Pontifícia Universidade Católica de São Paulo.

Recebido em: 30/03/2020

Aprovado em: 25/05/2020 